AIAA-2003-2105

\title{
ON THE DEVELOPMENT OF A SIX-DEGREE-OF-FREEDOM MODEL OF A LOW- ASPECT-RATIO PARAFOIL DELIVERY SYSTEM
}

\author{
Paul A. Mortaloni, ${ }^{\Re}$ Oleg A. Yakimenko, ${ }^{\text {" Vladimir N. Dobrokhodov, }}{ }^{*}$ Richard M. Howard ${ }^{\mathfrak{}}$ \\ Naval Postgraduate School, Department of Aeronautics and Astronautics, Monterey, CA 93943
}

\begin{abstract}
$\underline{\text { Abstract }}$
The future of the Army's air delivery mission includes the use of precision-guided autonomous airdrop methods to resupply troops in the field. High-glide systems, ram-air parafoil-based, allow for a safe standoff delivery as well as wind penetration. This paper addresses the development of a six-degree-offreedom model of a low-aspect ratio controllable parafoil-based delivery system. The model is equally suitable for modeling and simulation and for the design of guidance, navigation and control (GNC) algorithms. This gliding parafoil model was developed in the MATLAB/Simulink ${ }^{\circledR}$ environment. Apparent mass and inertia effects are included in the model. Initial test cases have been run to check model fidelity.
\end{abstract}

\section{$\underline{\text { Introduction }}$}

The tempo of the battlefield in today's Army is extremely fast-paced. The Desert Storm war demonstrated the rapid pace at which a land battle can be executed. The Army's transformation initiatives are geared towards increasing the ability of the Army to respond rapidly and improve the agility and mobility of its forces. A key part of this transformation is the ability to get materiel where it needs to be, when it needs to be there. In addition, the US Air Force desires to improve the survivability of its air delivery aircraft by increasing the ability to drop payloads from higher altitudes than currently dropped from and further from the drop zones. Therefore, the services require the ability to deliver payloads from high altitude, with large standoff to achieve precision accuracies from the desired impact point.

This paper is declared a work of the U.S. Government and is not subject to copyright protection in the United States.

${ }^{\Re}$ Graduate Student. Currently, Acting Air Delivery Division Chief, Yuma Proving Ground, Yuma, AZ, 85364; Member AIAA.

"Research Associate Professor, Associate Fellow AIAA. *National Research Council Research Associate; Member AIAA.

${ }^{\Im}$ Associate Professor; Senior Member AIAA.
Numerous papers in the area of parafoil system design have been published over the past 50 years. They cover the following major topics:

- Advanced computational methods for the 3D flow simulation around the parafoil canopy; ${ }^{1-3}$

- Wind-tunnel experiments, ${ }^{4-7}$

- Real drop experiments. ${ }^{8-18}$

Although each of these papers topics addresses the problem differently, they all share an important feature - verification of corresponding mathematical models using real drop data.

Despite the 50-year research effort, the aerodynamics of a flexible body such as a parafoil canopy still contains some unknowns and uncertainties. For instance, because of the flexible nature of a parafoil's canopy, even aerodynamic experiments in wind tunnels ${ }^{4}$ may provide variable data for both longitudinal and lateral channels, not explicitly applicable for the modeling.

Analysis of previous work ${ }^{11-13,15,19-22}$ that addresses model verification leads to the conclusion that major differences between them lie in the way authors account for the influence of numerous interrelated parameters on the motion of entire system. This paper does not intend to discuss various numerical techniques of parameter identification (PID) ${ }^{23}$ but briefly mentions the physical issues (multicriteria essence) behind the identification process. This paper employs the same methodology authors have already used for the PID of a controllable circular parachute. ${ }^{24,25}$ The key feature of this original technique is to separate the influence of different dominant factors (apparent mass terms, aerodynamic coefficients) by employing different portions of the flight test data.

The paper is organized as follows. The background section of the paper reviews existing parafoil models and discusses several modeling issues not completely resolved to date. Formulation of the problem follows next. The paper then proceeds with a development of the mathematical model of a double-skin parafoil. This includes the basic equations of motion in matrix form convenient for further implementation within the 
Mathworks MATLAB/Simulink environment. The apparent mass model is then presented. The following section provides analysis and computation of the aerodynamic forces and moments. The paper then contains examples of simulations including system response on certain control patterns. Preliminary results of the model's parameters identification based on comparison with the airdrop data available are also introduced. The paper ends with the summary of obtained results.

\section{Configuration of the Descending System}

The autonomously guided Pegasus delivery system is comprised of a ram-air canopy, a GPS-based guidance and control unit, and payload. A photo of the system is shown in Figure 1.

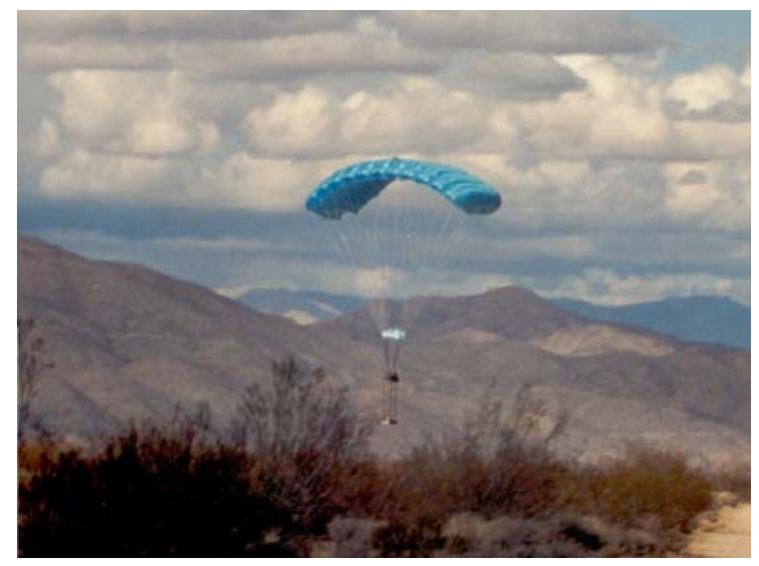

Fig. 1 Pegasus parafoil (from Ref. 26)

The main canopy is an eleven-cell ram-air design. It is made of 1.1-ounce F-111 nylon with cotton reinforcement. The rectangular planform is $575 \mathrm{sq}$. $f t$ with a wingspan of $40 \mathrm{ft}$. The 2D airfoil shape is a customized proprietary design developed by FXC Corporation. The system payload can be varied from
400 to $600 \mathrm{lbs}$ without exceeding the performance range of the ram-air canopy. Under the current test configuration, the payload is a wooden rectangular box, rigged to $500 \mathrm{lbs}$.

The guidance and control unit is suspended between the canopy and the payload. It consists of an airborne computer with embedded control logic, GPS receiver, IMU and compass. Two control actuators provide control inputs to the control lines attached to the left and right trailing edges of the canopy. The control surfaces of the canopy can be deflected symmetrically (up to 18 inches) for pitch control and asymmetrically for lateral control.

\section{$\underline{\text { Parafoil Model }}$}

The model was derived using general equations of fluid dynamics. $^{21,27}$

The final form of the equations of motion of the whole system as a rigid parafoil-payload body ${ }^{17,18}$ was written in matrix form

$$
\dot{V}^{\star T}=A^{-1}\left\{\left[\begin{array}{l}
F \\
M
\end{array}\right]-(\Sigma+U) A V^{\star}\right\}
$$

where the following vector notation was used

$$
\begin{gathered}
V^{\star}=\left[\begin{array}{llllll}
V_{1} & V_{2} & V_{3} & \omega_{1} & \omega_{2} & \omega_{3}
\end{array}\right]^{T} \\
\dot{V}^{\star}=\left[\begin{array}{llllll}
\dot{V}_{1} & \dot{V}_{2} & \dot{V}_{3} & \dot{\omega}_{1} & \dot{\omega}_{2} & \dot{\omega}_{3}
\end{array}\right] \\
{\left[\begin{array}{l}
F \\
M
\end{array}\right]=A \dot{V}^{\star T}+\Sigma A V^{\star}+U A V^{\star}}
\end{gathered}
$$

The matrices $A, \Sigma$ and $U$ were defined as follows

$$
A=\left[\begin{array}{cccccc}
m+\alpha_{11} & 0 & \alpha_{13} & 0 & \alpha_{15}+m z_{s} & 0 \\
0 & m+\alpha_{22} & 0 & \alpha_{24}-m z_{s} & 0 & \alpha_{26}+m x_{s} \\
\alpha_{13} & 0 & m+\alpha_{33} & 0 & \alpha_{35}-m x_{s} & 0 \\
0 & \alpha_{24}-m z_{s} & 0 & I_{11}+\alpha_{44} & 0 & I_{13}+\alpha_{46} \\
\alpha_{15}+m z_{s} & 0 & \alpha_{35}-m x_{s} & 0 & I_{22}+\alpha_{55} & 0 \\
0 & \alpha_{26}+m x_{s} & 0 & I_{13}+\alpha_{46} & 0 & I_{33}+\alpha_{66}
\end{array}\right]
$$




$$
\begin{gathered}
\Sigma=\left[\begin{array}{cccccc}
0 & -\omega_{3} & \omega_{2} & 0 & 0 & 0 \\
\omega_{3} & 0 & -\omega_{1} & 0 & 0 & 0 \\
-\omega_{2} & \omega_{1} & 0 & 0 & 0 & 0 \\
0 & 0 & 0 & 0 & -\omega_{3} & \omega_{2} \\
0 & 0 & 0 & \omega_{3} & 0 & -\omega_{1} \\
0 & 0 & 0 & -\omega_{2} & \omega_{1} & 0
\end{array}\right] \\
U=\left[\begin{array}{cccccc}
0 & 0 & 0 & 0 & 0 & 0 \\
0 & 0 & 0 & 0 & 0 & 0 \\
0 & 0 & 0 & 0 & 0 & 0 \\
0 & -V_{3} & V_{2} & 0 & 0 & 0 \\
V_{3} & 0 & -V_{1} & 0 & 0 & 0 \\
-V_{2} & V_{1} & 0 & 0 & 0 & 0
\end{array}\right]
\end{gathered}
$$

In these equations $\mathrm{m}$ is the total mass of the system, $I_{\mathrm{ij}}$ are the moments of inertia, $\alpha_{\mathrm{ij}}$ are the apparent mass and inertia terms, $V_{\mathrm{i}}$ are the velocity components, $\omega_{\mathrm{i}}$ - the angular velocities, $z_{\mathrm{s}}$ and $x_{\mathrm{s}}$ are the vertical and longitudinal moment arms from particular component from the origin of the bodyfixed coordinate frame.

Implementation was carried out in the Mathworks MATLAB/Simulink environment similarly to how it was done for the circular parachute in a previous study. ${ }^{20,21}$ The general view of the Simulink model is presented in Figure 2.

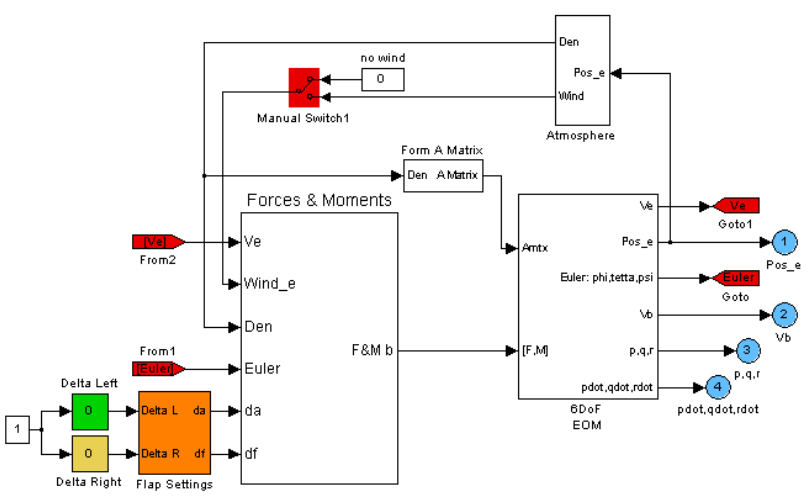

\section{Aerodynamics Model}

The only available data on the aerodynamic coefficients was the wind tunnel data from Refs. 4 and 7 and computational fluid dynamics data obtained for the steady state turn in Ref. 28. However it was impossible to implement this data directly. While Refs. 7 and 28 contain the data just for one single point in terms of dependence on the angle of attack, the data in Ref. 4 despite of the richness of different dependences for three aspect ratios is somewhat incomplete and contradictory. Figures 3-7 give an example of the data on some lateral and longitudinal coefficients after some necessary corrections. It is seen, that the data is quite nonlinear, non-consistent and obviously use the different scale for the angle of attack. After thorough analysis of the data it was assumed that a setup for the wind tunnel experiment included about $10^{\circ}$ rigging angle so that the angle of attack axis for the longitudinal channel (Figures 6 and 7) should be shifted left by this angle.

Instead of modeling the aerodynamic coefficients along the full range of angles of attack $\left(\left[-10^{\circ}, 80^{\circ}\right]\right)$ it was suggested to replace them with the linear dependences within the operable range of angles of attack $\left(\left[0^{\circ}, 20^{\circ}\right]\right)$ as shown by appropriate formulas on Figures 3-7. Not only this provides a reasonable behavior and gives an acceptable accuracy but it also enables the use simple PID technique where only a few parameters for each dependence have to be optimized.

After careful analysis and preliminary simulation runs the applied aerodynamics model was developed as the database for all major aerodynamic coefficients expressed as functions of several input parameters. The longitudinal and lateral-directional aerodynamic coefficients depend on the angle of attack $(\alpha)$, sideslip angle $(\beta)$, symmetrical flaps deflection $\left(\delta_{f}=\min \left(\delta_{\text {left }}, \delta_{\text {right }}\right) \in[0 ; 1]\right)$, and differential flaps deflection $\left(\delta_{a}=\delta_{\text {left }}-\delta_{\text {right }}\right)$ as shown in the following equations.

Fig. 2 Simulink model

$$
\begin{aligned}
& C_{D}=0.14+\left(0.25+0.2 \delta_{f}\right) C_{I}^{2} \\
& C_{Y}=(-0.005-0.0001 \alpha) \beta+(-0.007+0.0012 \alpha) \delta_{a} \\
& C_{L}=0.0375\left(\alpha+10^{\circ}\right)+0.1\left(2 \delta_{f}+\left|\delta_{a}\right|\right)
\end{aligned}
$$




$$
\begin{aligned}
& C_{1}=(0.005-0.0018 \alpha) \beta-0.0063 \delta_{a}-\frac{b}{2|V|}(0.15 p+0.0775 r) \\
& C_{m}=-0.33+\frac{d m_{1}}{m_{1}+m_{2}}\left(\frac{1}{C}+\frac{\rho C_{B_{o}}}{2 W / S}\right)\left(C_{D} C_{L}\right)\left(\begin{array}{c}
\cos \left(\alpha+8^{\circ}\right) \\
-\sin \left(\alpha+8^{\circ}\right)
\end{array}\right)-6.39 \frac{q C}{|V|} \\
& C_{n}=(0.007-0.0003 \alpha) \beta+(0.019-0.0008 \alpha) \delta_{a}+\frac{b}{2|V|}(0.023 p-0.0936 r)
\end{aligned}
$$

where $C_{L}, C_{D}$, and $C_{Y}$ are the lift, drag and side-force coefficients; $C_{l}, C_{m}$, and $C_{n}$ are the rolling moment, pitch moment, and yawing moment coefficients; $p, q$, and $r$ are the rolling, pitch, and yawing moments; $b$ and $c$ are the inflated span and chord; $V$ is the total velocity; $m_{1}$ and $m_{2}$ are the payload and canopy masses, respectively. The rigging angle of $8^{\circ}$ and $\alpha_{C_{L}=0}=-10^{\circ}$ were applied.

The derivation of the formula for the coefficient $C_{m}$ was based on the analysis presented in Ref. 19.

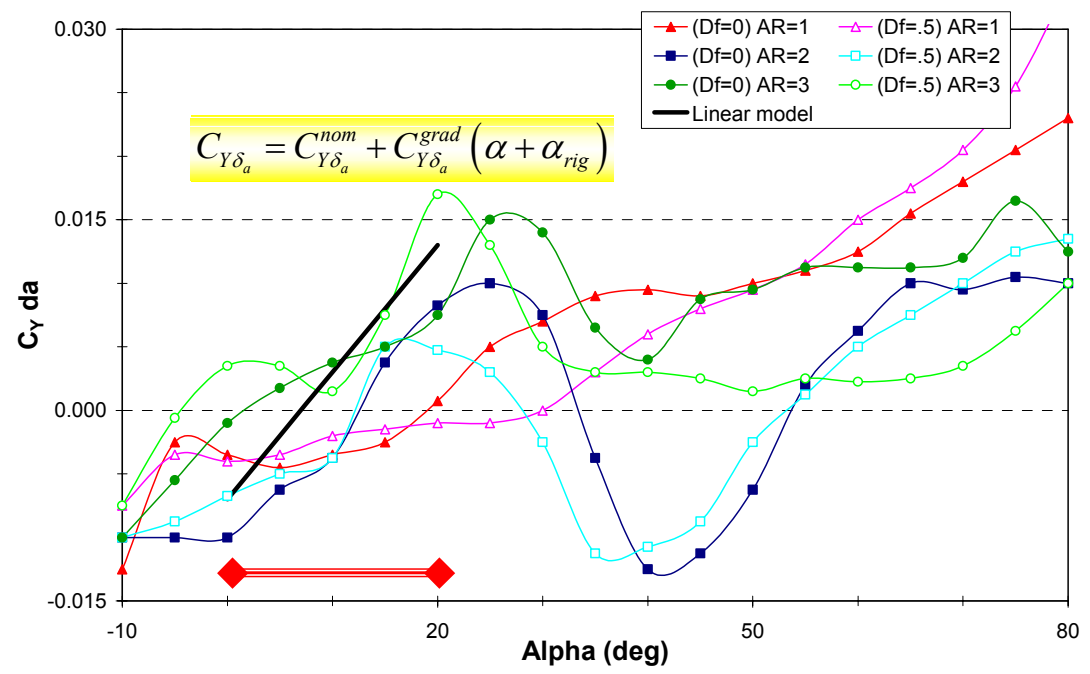

Fig. 3 Modeling of the coefficient $C_{Y \delta a}$

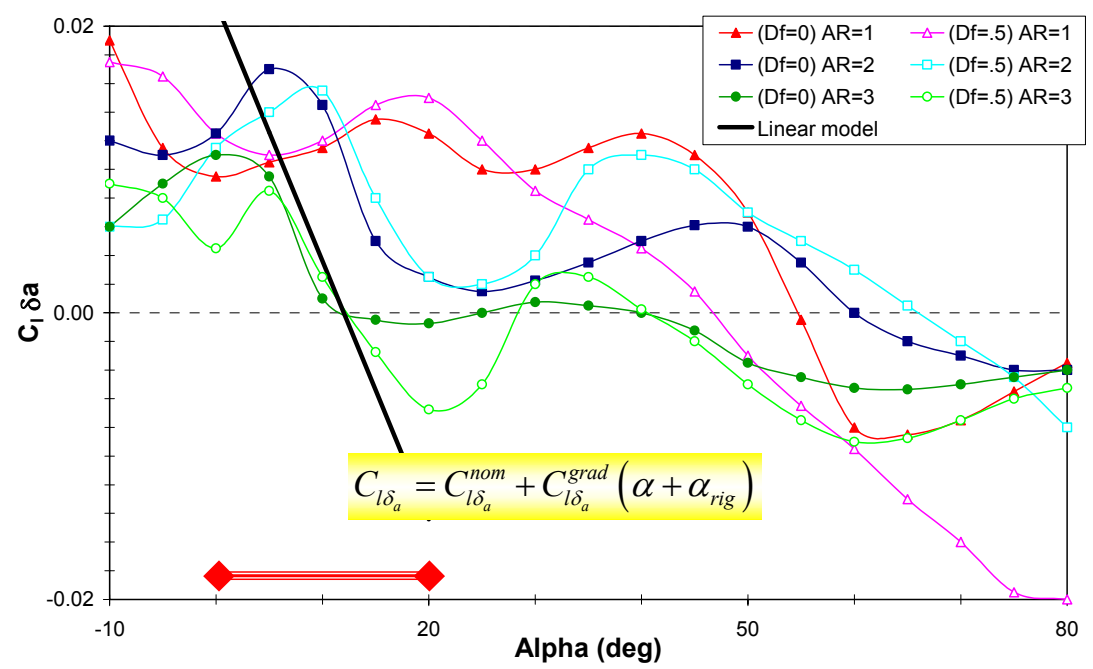

Fig. 4 Modeling of the coefficient $C_{l \delta a}$ 


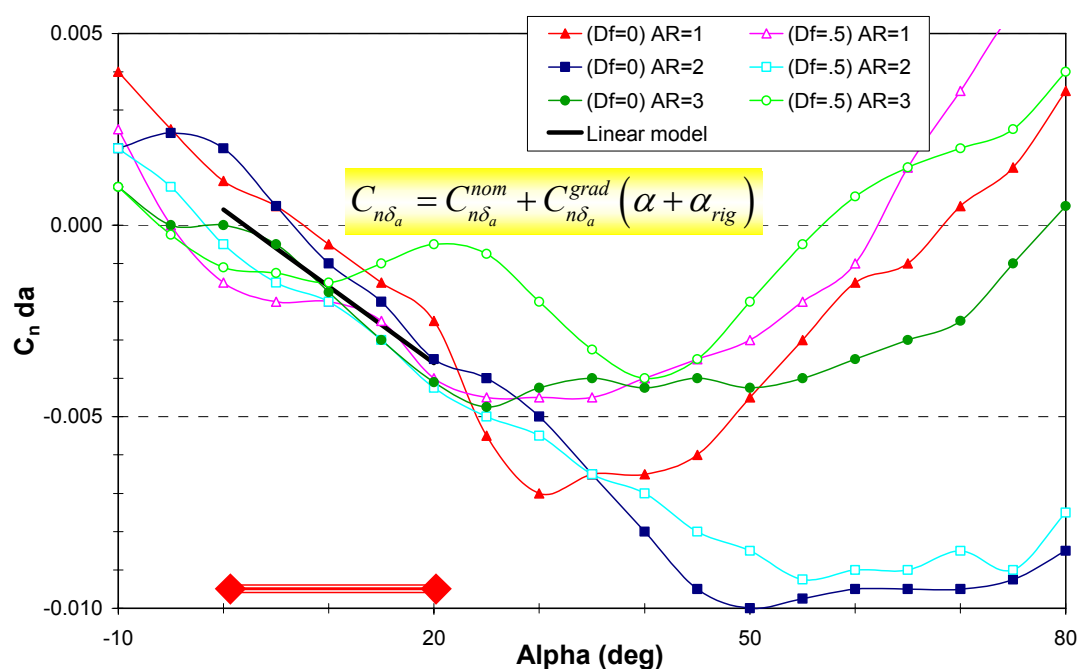

Fig. 5 Modeling of the coefficient $C_{n \delta a}$

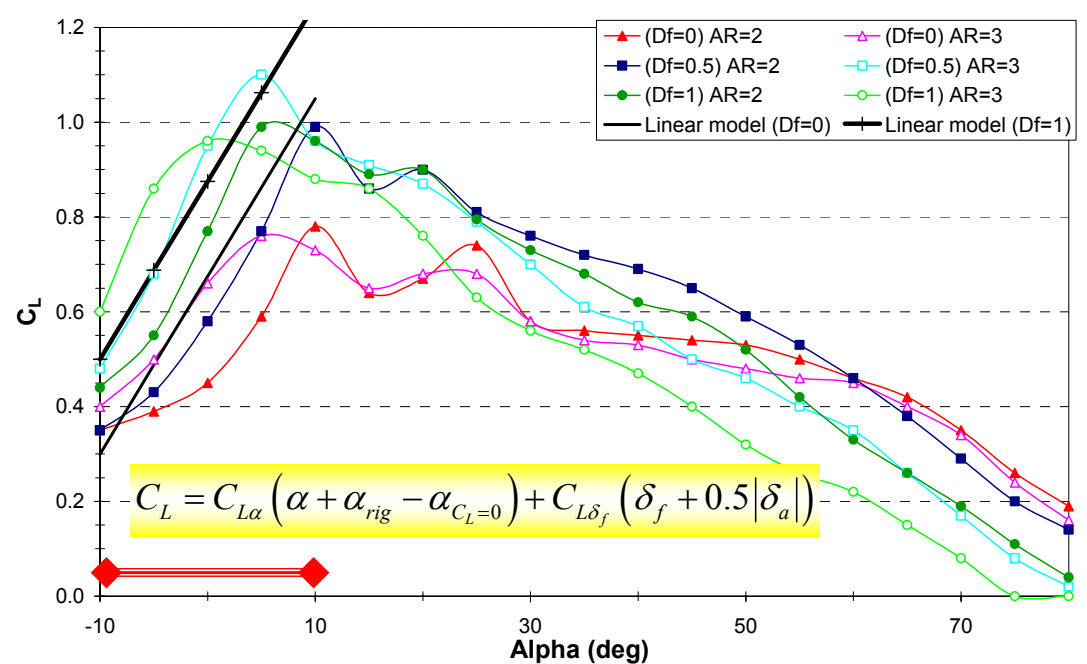

Fig. 6 Modeling of the coefficient $C_{L}$

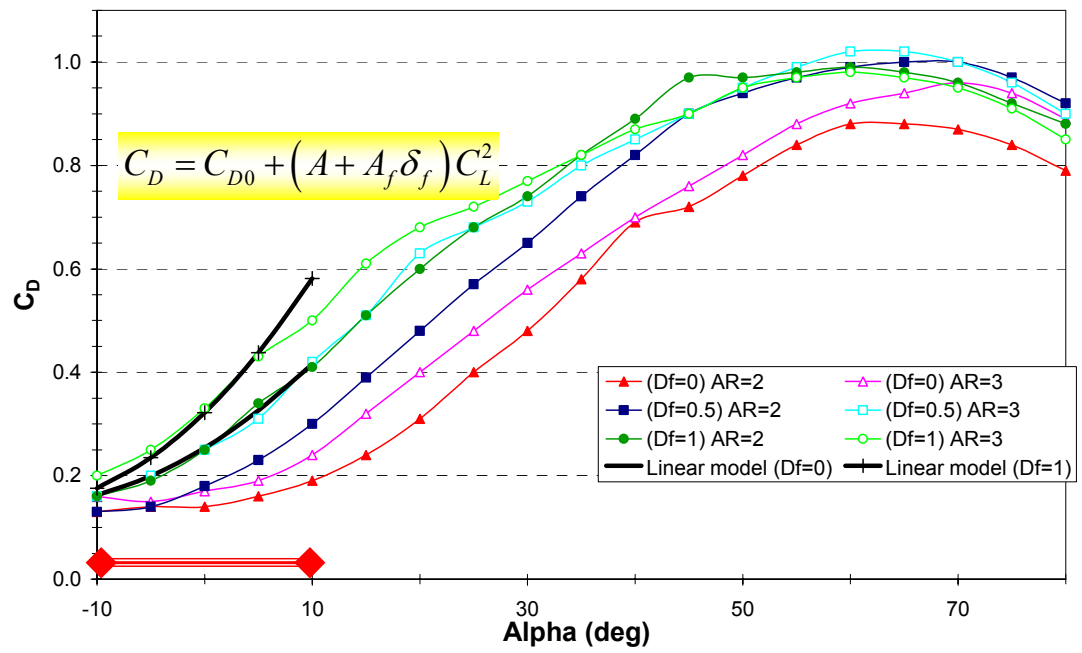

Fig. 7 Modeling of the coefficient $C_{D}$ 


\section{$\underline{\text { Apparent Mass Model }}$}

In general the apparent mass tensor $A$ (5) contains 36 elements that maybe unique in a real fluid. For ideal fluid, however, the tensor $A$ has a symmetrical form, leaving a maximum of 21 distinct terms. In the case of a body with one plane of symmetry, tensor $A$ can be further reduced to 12 unique components. . $^{21,29,30}$

During descent of a fully deployed symmetric parafoil canopy, its added mass terms are functions of air density and are defined to be the algebraic functions of cylindrical volume and parafoil geometry multiplied by empirical scaling coefficients. ${ }^{24}$ Off-diagonal terms in (5) are introduced as corresponding values of static and inertial moments multiplied by correction coefficients. These unknown so far coefficients, which by the way depend on the state of control surfaces, are left in (5) for the further PID.

\section{$\underline{\text { Preliminary Simulation Results }}$}

The model response on the control inputs is discussed in this section.

Figure 8 indicates the longitudinal response to a pulse input of $\delta_{f}=0.5$ after the parafoil was trimmed in flight at an altitude of $3000 \mathrm{~m}$. With flap deflection, the angle of attack increases, pitch angle increases, and flight-path angle is steeper, as is expected. A short-period type of dynamic response is also noted, which is heavily damped.

Figure 9 indicates the trajectory due to the asymmetric input of an aileron. Figure 10 shows rollrate and yaw-rate responses due to the control input. The steady-state bank angle is about $4^{\circ}$ and the steady yaw rate is $2.8 \%$.

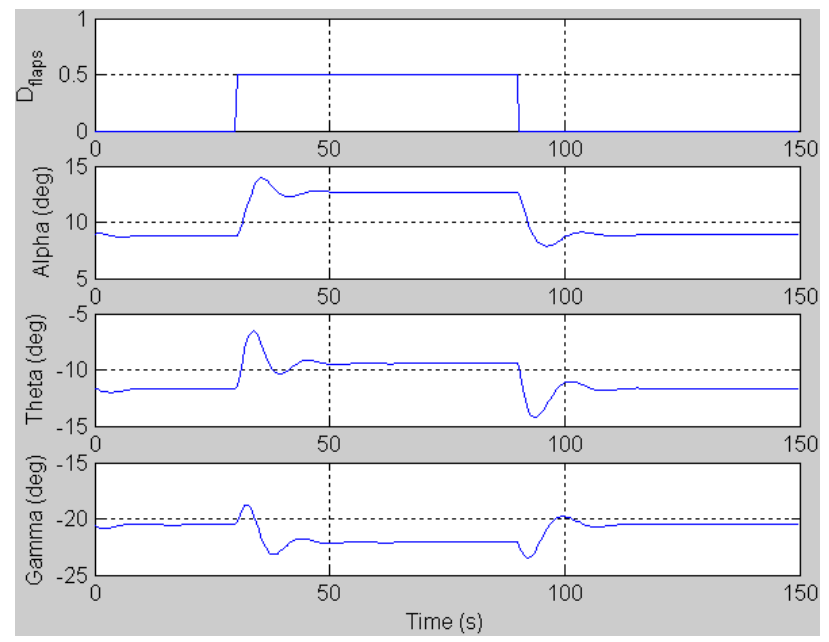

Fig. 8 Longitudinal response to flap deflection

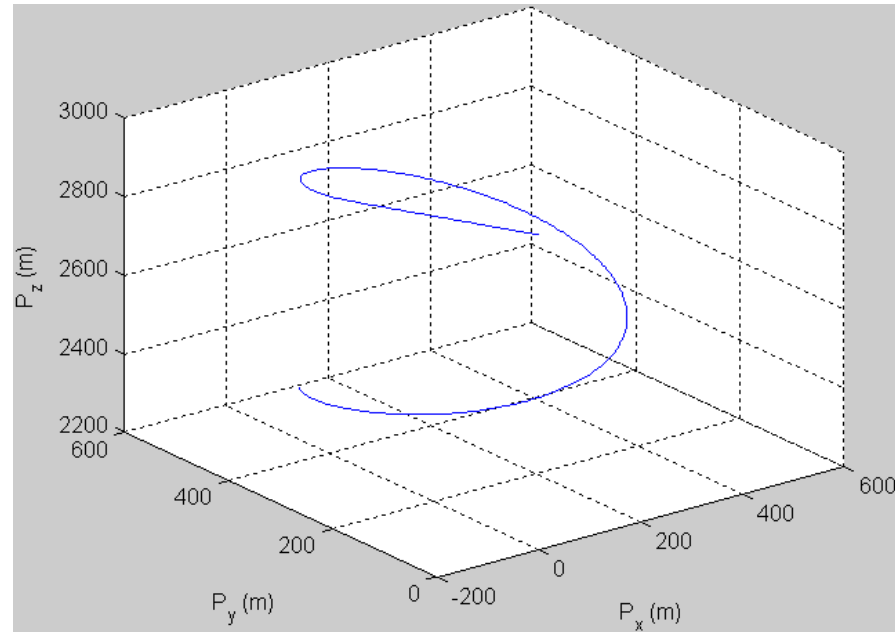

Fig. 9 Trajectory due to aileron deflection 


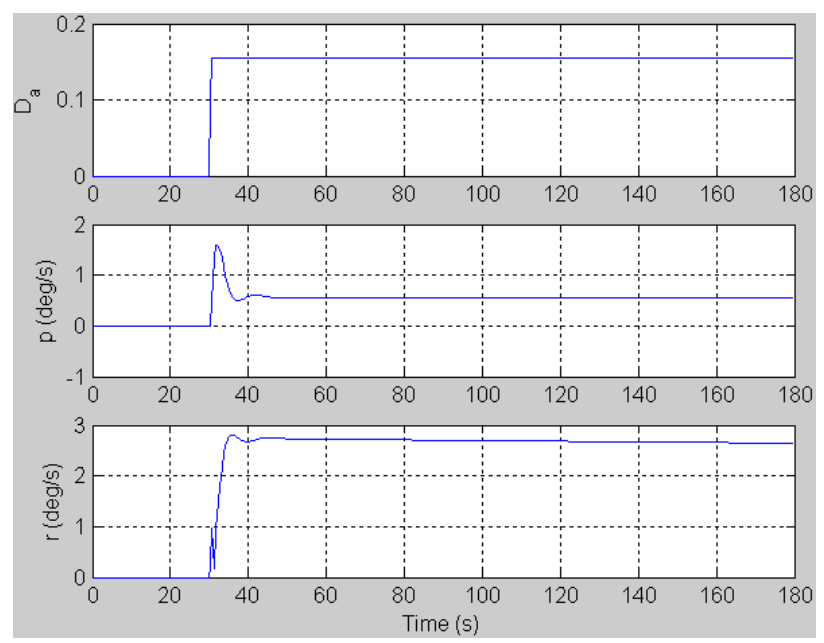

Fig. 10 Roll and yaw rate responses to aileron input

\section{Trajectory Data Source}

The following airborne suite of sensors has been used to obtain the objective information during this study:

- IMU block provided the following data sampled at $100 \mathrm{~Hz}$ : Roll Rate, Pitch Rate, Yaw Rate, X Acceleration, Y Acceleration, Z Acceleration;

- Compass provided attitude data measured in the body frame and sampled at $4 \mathrm{~Hz}$;

- GPS unit provided the following data sampled at $10 \mathrm{~Hz}$ : Latitude, Longitude, Altitude, Ground
Speed, Track Angle, Velocity East, Velocity North, Velocity Up.

The WindPack dropsonde, dropped at the same time as the descending system, provided the real-time wind profile update with the frequency of $10 \mathrm{~Hz}$. A sample of vertical profiles for both parafoil and WindPack dropsonde is shown on Figure 11.

The data collected during the only (so far) flight test was analyzed and used as a truth data for the PID.

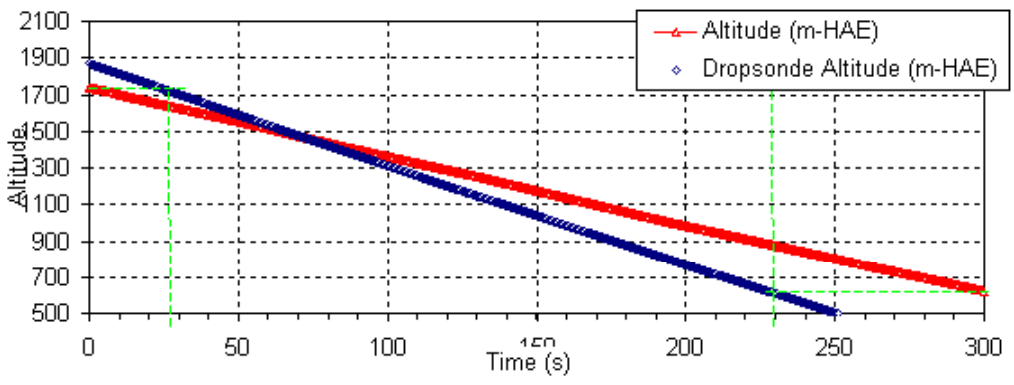

Fig. 11 Example of vertical profiles versus time

\section{Parameter Identification Technique}

For the case of the rigid wing one of the wellestablished system ID tools may be used to identify its aerodynamic characteristics. In the parafoil case however this approach is impossible. Moreover, the estimation of the apparent mass terms even for the case of the fixed-geometry parafoil is nonintuitive. ${ }^{21,28,29}$ The apparent mass has the following important property: it changes with orientation of the associated motion. Therefore, appropriate choice of truth data can obviously identify the apparent mass terms that dominate specific motion. A non-standard nonlinear system PID technique including employment of the multicriteria optimization ${ }^{31}$ to find reasonable ranges of the optimization parameters and zero-order Hooke-Jeeves method ${ }^{32}$ to actually define the best solutions for optimization parameters was applied to tune the initial aerodynamic dependences and apparent mass terms as well. Although the PID still continues, Figures 12-14 show some preliminary results obtained so far. 

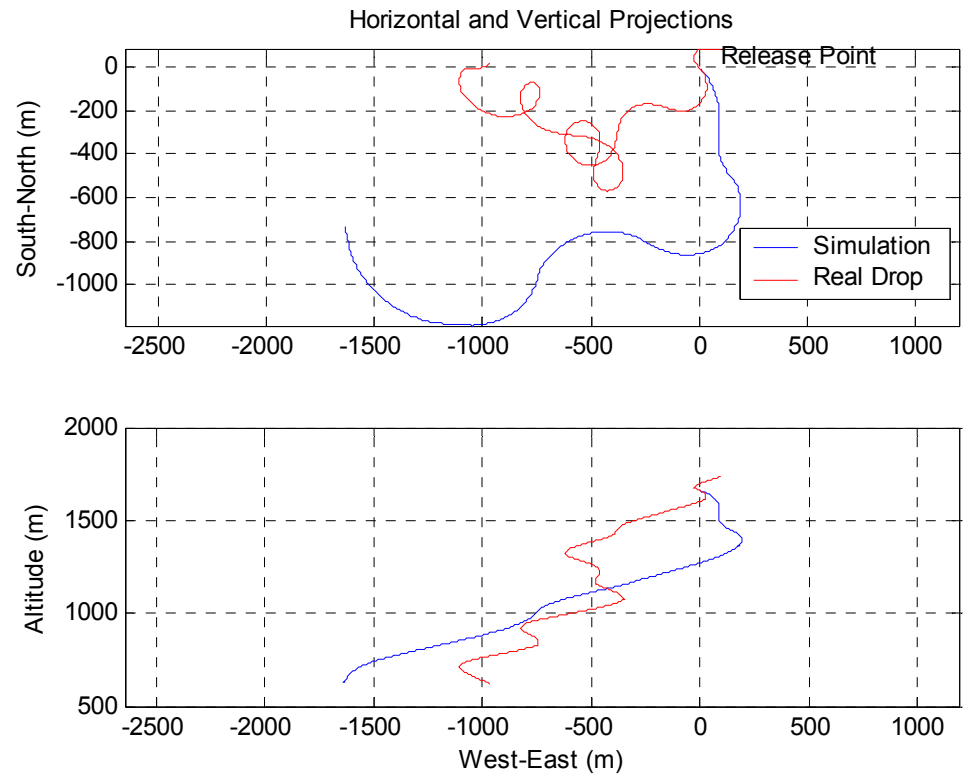

Fig. 12 Comparison of the flight test data with the original (not-tuned) model
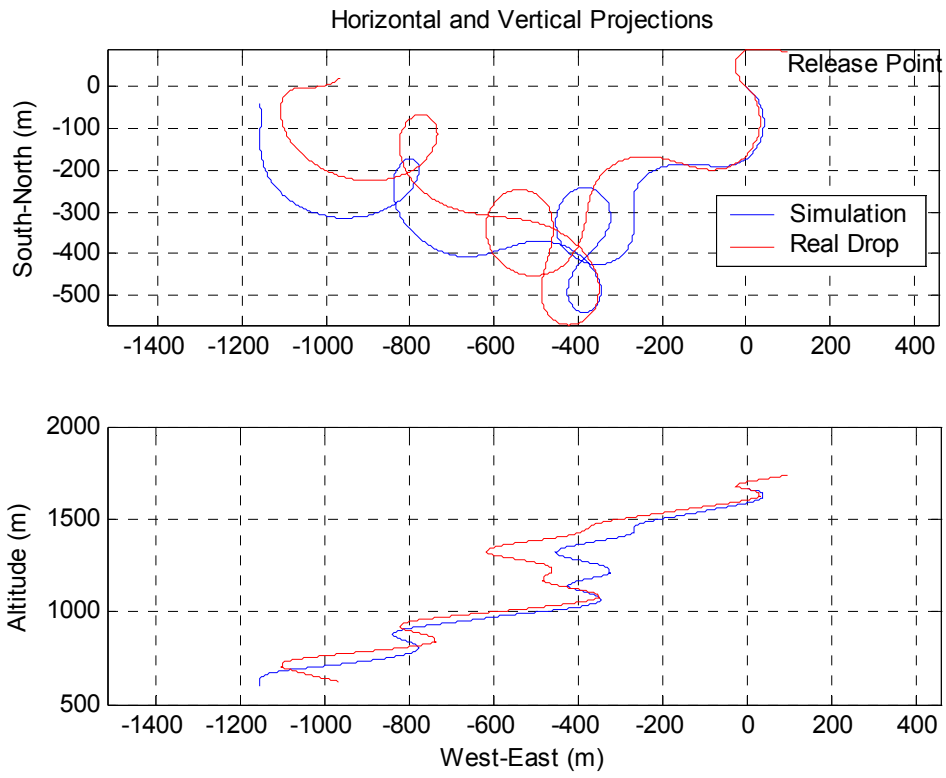

Fig. 13 Comparison of the flight test data with the tuned model

While the original model matches the integral behavior of the system in terms of glide ratio (2.5) and vertical velocity $(3.7 \mathrm{~m} / \mathrm{s})$ fairly well some correction was needed to match the turn rate $6 \%$ demonstrated during the flight tests.

Figure 12 demonstrates the discrepancy of the original model in the lateral channel. Figure 13 shows how the changing of the only coefficient $C_{n \delta a}^{\text {nom }}$ from 0.019 to 0.032 improves the model. Further improvement involving more coefficients is also possible (Figure 14). However in this case the developed PID technique involves finding and using only Pareto-optimal ${ }^{31}$ solutions, which do not make other criteria (vertical channel matching, eigen frequencies, etc.) worse. 

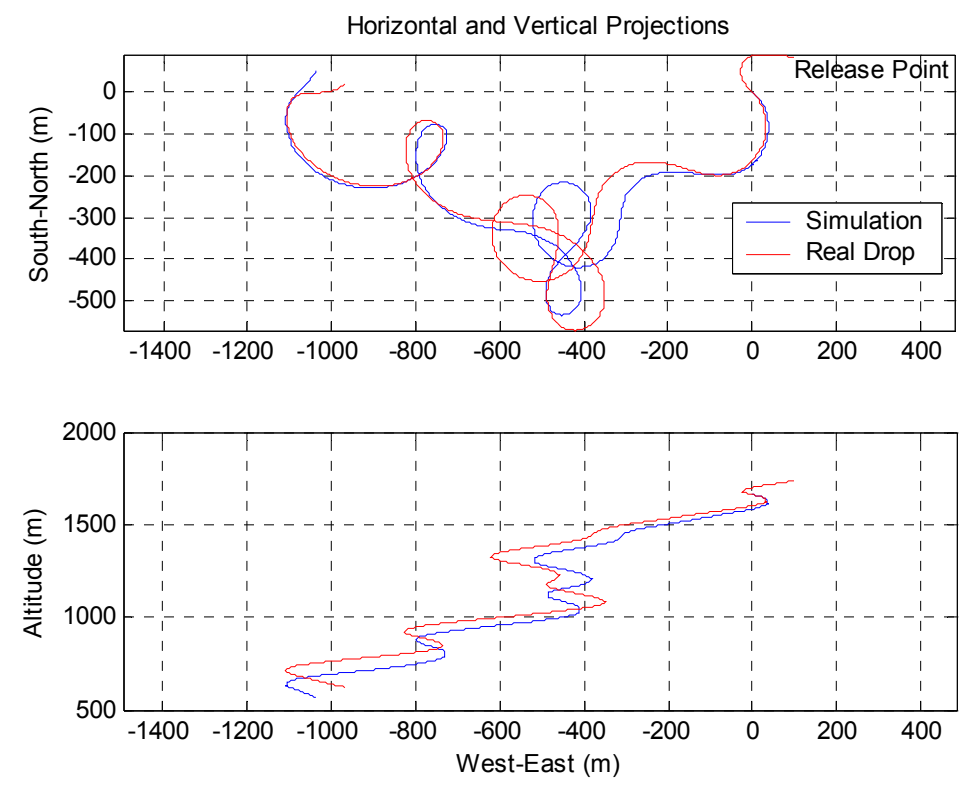

Fig. 14 Example of the further tuning

\section{$\underline{\text { Conclusions }}$}

The complete $6 \mathrm{DoF}$ model of the parafoil system has been developed and realized within the MathWorks MATLAB/Simiulink environment. The model demonstrates an adequate response for the control inputs and matches the result of the flight tests well. A nonlinear system identification technique is currently being applied to tune the model and correct the apparent mass terms. The authors intend to present more PID results upon the completion of the tests.

\section{Acknowledgments}

The work was performed under research grants from the US Army Soldier Systems Center and the US Army Yuma Proving Ground under the technical guidance of Richard Benney and Scott Dellicker, respectively. The authors are grateful for their continued support.

\section{$\underline{\text { References }}$}

${ }^{1}$ Alaibadi, S.K., Garrard, W.L., Karlo, V., Mittal, T.E., Tezduyar, T.E., and Stein, K.R., "Parallel finite element computations of the dynamics of large ram air parachutes," AIAA-95-1581, Proceedings of 13th AIAA Aerodynamic Decelerator Systems Technology Conference and Seminar, Clearwater, Florida, 1995.

${ }^{2}$ Tezduyar, T., Karlo, V., and Garrad, W. "Advanced Computational Methods for 3D Simulation of Parafoils," AIAA-99-1712, Proceedings of 15th AIAA Aerodynamic
Decelerator Systems Technology Conference and Seminar, Toulouse, France, June 10-13, 1999.

${ }^{3}$ Chatzikonstantinou, T., "Recent Advances in the Numerical Analysis of Ram Air Wings. The Three Dimensional Simulation Code "PARA3D"," AIAA-931203.

${ }^{4}$ Ware, G. M., and Hassell, J. L., "Wind Tunnel Investigation of Ram-Air-Inflated All-Flexible Wings of Aspect Ratios 1.0 to 3.0", NASA TM SX-1923, December 1969.

${ }^{5}$ Nicolaides, J. D., "Parafoil Wind Tunnel Tests", AFFDLTR-70-146, Notre Dame University, June 1971.

${ }^{6}$ Matos, C., Mahalingam, R.G., Ottinger, G., Klapper, J., Funk, R., and Komerath, N.M., "Wind tunnel measurements of Parafoil Geometry and Aerodynamics," AIAA-98-0606, Proceedings of $36^{\text {th }}$ Aerospace Science Meeting and Exhibition, Reno, NV, January 12-15, 1998.

${ }^{7}$ Entchev R.O., and Rubenstein, D., "Modeling Small Parafoil Dynamics," Final Report \#16.622, 2001 (http://web.mit.edu/rrodin/www/projects/parafoil/\#tth_sEc A).

${ }^{8}$ Komerath, N.M., Funk, R., Mahalingam, R.G., and Matos, C., "Low Speed Aerodynamis of the X-38 CRV: Summary of Research NAG9-927, 5/97-4/98," GITAER-EAG-98-03, June 1998.

${ }^{9}$ Goodrick, T.F., "Comparison of Simulation and Experimental Data for a Gliding Parachute in Dynamic Flight," AIAA-81-1924, Proceedings of 7th AIAA Aerodynamic Decelerator and Balloon Technology Conference, San Diego, CA, October 21-23, 1981.

${ }^{10}$ Stein, J., Machin, R., and Muratore, J., "An Overview of the X-38 Prototype Crew Return Vehicle Development and 
Test Program", AIAA-99-1703, Proceedings of AIAA Weakly Ionized Gases Workshop, 3rd, Norfolk, VA, Nov. $1-5,1999$.

${ }^{11}$ Iacomini, C.S., and Cerimele, C., "Lateral-Directional Aerodynamics From A Large Scale Parafoil Test Program", AIAA-99-1731, Proceedings of AIAA Weakly Ionized Gases Workshop, 3rd, Norfolk, VA, Nov. 1-5, 1999.

${ }^{12}$ Iacomini, C.S., and Madsen, C., "Investigation of Large Scale Parafoil Rigging Angles: Analytical and Drop Test Results", AIAA-99-1752, Proceedings of AIAA Weakly Ionized Gases Workshop, 3rd, Norfolk, VA, Nov. 1-5, 1999.

${ }^{13}$ Iacomini, C.S., and Cerimele, C., "Longitudinal Aerodynamics From A Large Scale Parafoil Test Program", AIAA-99-1732, Proceedings of AIAA Weakly Ionized Gases Workshop, 3rd, Norfolk, VA, Nov. 1-5, 1999.

${ }^{14}$ Smith, J., and Bennet, T., "Development of the NASA X38 Parafoil Landing System", AIAA-99-1730, Proceedings of AIAA Weakly Ionized Gases Workshop, 3rd, Norfolk, VA, Nov. 1-5, 1999.

${ }^{15}$ Madsen, C., and Cerimele, C., "Updated Flight Performance and Aerodynamics from a Large Scale Parafoil Test Program", AIAA-00-4311, Proceedings of AIAA Modeling and Simulation Technologies Conference, Denver, CO, Aug. 14-17, 2000.

${ }^{16}$ Smith, J., and Bennet, T., "Design and Testing of the X38 Spacecraft Primary Parafoil", AIAA-99-1730, Proceedings of AIAA Modeling and Simulation Technologies Conference, Denver, CO, Aug. 14-17, 2000.

${ }^{17}$ Strickert, G., and Jann, T., "Determination of the Relative Motion between Parafoil Canopy and Load Using Advanced Video-Image Processing Techniques," AIAA99-1754, Proceedings of the 3rd AIAA Workshop on Weakly Ionized Gases, Norfolk, VA, November 1-5, 1999.

${ }^{18}$ Strickert, G., and Witte, L., "Analysis of the Relative Motion in a Parafoil-Load System," AIAA-2001-2013, Proceedings of the 16th AIAA Aerodynamic Decelerator Systems Technology Conference, Boston, MA, May 15-18, 2001.

${ }^{19}$ Goodrick, T.F., "Theoretical Study of the Longitudinal Stability of High-Performance Gliding Airdrop Systems," AIAA-75-1394, Proceedings of 5th AIAA Aerodynamic Decelerator Systems Conference, Albuqurque, NM, 1975.

${ }^{20}$ Goodrick, T.F., " Estimation of Wind Effect on Gliding Parachute Cargo Systems using Computer Simulation," AIAA-70-1193, Proceedings of AIAA Aerodynamic
Decelerator Systems Technology Conference, Dayton, Ohio, September 14-16, 1970.

${ }^{21}$ Cockrell, D.J., and Doherr, K.-F, "Preliminary Consideration of Parameter Identification Analysis from Parachute Aerodynamic Flight Test Data," AIAA-91-1940.

${ }^{22}$ Cockrell, D.J., and Doherr, K.-F, "Advances in the Application of parameter identification Analysis Techniques to Parachute Aerodynamic Test Data," AIAA84-0799, Proceedings of 8th AIAA Aerodynamic Decelerator and Balloon Technology Conference, Hyannis, Massachusetts, April 2-4, 1984.

${ }^{23}$ Hamel, P.G., and Jategaonkar, R.V., "Evolution of Flight Vehicle System Identification, Journal of Aircraft," vol. 33 (1), 1996, pp.9-28.

${ }^{24}$ Dobrokhodov, V, Yakimenko, O., and Junge, C., "SixDegree-of-Freedom Model of a Controllable Circular Parachute", Proceedings of AIAA Atmospheric Flight Mechanics Conference, Monterey, CA, August 5-8, 2002.

${ }^{25}$ Dobrokhodov, V, Yakimenko, O., and Junge, C., "Simulink Implementation of the 6DoF Model of Controlled Circular Parachute", Proceedings of AIAA Modeling and Simulation Technologies Conference, Monterey, CA, August 5-8, 2002.

${ }^{26}$ Sego, K., Jr., "Development of a High Glide, Autonomous Aerial Delivery System - Pegasus 500 (APADS)," AIAA Paper 2001-2073.

${ }^{27}$ Lingard, J.S., Gliding Parachutes, Parachutes Systems Technology Short Course, Minneapolis, Minnesota, October 1998.

${ }^{28}$ Brown, G., "Parafoil Steady Turn Response to Control Input”, AIAA Paper No. AIAA-93-1241, 1993.

${ }^{29}$ Lissaman, P., and Brown, G., "Apparent Mass Effects on Parafoil Dynamics," AIAA-93-1236, Proceedings of 12th AIAA Aerodynamic Decelerator Systems Technology Conference and Seminar, London, England, May 10-13, 1993.

${ }^{30}$ Barrows, T.M., "Apparent Mass of Parafoils with Spanwise Camber," AIAA 2001-2006, Proceedings of 16th AIAA Aerodynamic Decelerator Systems Technology Conference and Seminar, Boston, MA, May 21-24, 2001.

${ }^{31}$ Statnikov, R.B. Multicriteria Design. Optimization and Identification, Kluwer Academic Publishers, Dordrecht/Boston/London, 1999.

${ }^{32}$ Hooke, R., and T.A. Jeeves ““'Direct Search” Solution of Numerical and Statistical Problems," J. ACM, April, 1961, pp.212-221. 